\title{
Mentoring: An Essential Catalyst in Professional Development of Teaching Faculty and Medical Students
}

\author{
Sonali Sharma', Sudhanshu Kacker ${ }^{2}$ \\ ${ }^{1}$ Professor and Head, Department of Biochemistry, ${ }^{2}$ Professor and Head, Department of Physiology, \\ RUHS College of Medical Sciences, Jaipur.
}

\begin{abstract}
Introduction: New entrants to medical colleges require achieving balance and developing study skills in the medical course. The process of mentoring thus involves several essential steps including transfer of knowledge and skills, learning effective communication, identifying the needs of the learner and acquiring techniques that are effective. The aim of the present study was to facilitate the student's performance in the subject and to evaluate the effectiveness of mentorship programme.
\end{abstract}

Methodology: A cross sectional study was conducted on one hundred second semester MBBS students in the Department of Biochemistry, RUHS College of Medical Sciences, Jaipur. Mentorship programme was implemented over a period of four months. The marks of second semester were compared with the marks of first semester to analyse effectiveness of mentorship programme in context to improvement in performance. Database was collected in the form of feedback questionnaire. A theoretical thematic analysis was made and statistical analysis using t-test was done.

Results: The mean \pm SD levels of theory and practical marks were statistically significant $(p<0.0001)$ in second semester when compared with marks of first semester examination. The transition of mentees to a higher score category post mentorship programme was observed. The trend was similar in theory and practical marks.

Conclusion: Mentorship programme raises the performance bar of students and fosters the well being and professional growth of students. Role of mentors as teachers is enhanced. Institutions need to encourage and recognize the value of a mentoring relationship.

\section{INTRODUCTION}

Navigating through medical course is a challenge. New entrants require achieving balance and developing study skills in the medical course which is identical to a marathon which keeps going and going. The teacher-student relationship in context to individualised learning has declined in medical education. Much emphasis has been placed on creating and fostering mentoring relationships in medicine'. Medical mentoring is 'a personal process that combines role modelling, apprenticeship and nurturing ${ }^{\prime 2}$.

The word mentor originally derives from the fictional character Mentor in Homer's Odyssey who educated and shaped the ethical character of Telemachus during his transition to manhood ${ }^{3}$. Many definitions of mentoring are in use. The one most frequently cited in English scientific literature (SCOPME") is "A process whereby an experienced, highly regarded, empathetic person (the mentor) 
guides another (usually younger) individual (the mentee) in the development and re-examination of their own ideas, learning, and personal and professional development. The mentor, who often (but not necessarily) works in the same organization or field as the mentee, achieves this by listening or talking in confidence to the mentee."

Faculty is one of the most valuable resource in an institute. Crosby has quoted that mentoring is a brain to pick, an ear to listen and a push into the right direction. A mentor should Motivate, Empower and encourage, Nurture self confidence, Teach by example, Offer wise counsel and Raise the performance bar ${ }^{5}$. The process of mentoring thus involves several essential steps, including transfer of knowledge and skills, learning effective communication, identifying the needs of the learner and acquiring techniques that are effective. Mentoring requires dedication, investment of time and resources. A mentor may not be able to excel at each role, however, what is more important is that the mentor performs his role to determine what will be most helpful to his/ her mentee.

A survey of 2879 emergency medicine residents indicated that interest in an academic career was correlated with more available role models and mentors ${ }^{6}$. Mentoring is also seen as critical for the advancement of science in internal medicine, paediatrics, primary care and gynaecology $y^{7-10}$. Mentoring sets the stage for mentees to approach, define, and mould their future and to develop networks of peers, co- investigators, and colleagues".

Occasionally, the mentor/mentee relationship may be either non-productive or dysfunctional. Several authors also point out the difficulties and pitfalls of mentoring ${ }^{12-14}$ : the short duration of medical school courses, constant time pressure, a lack of communication, markedly different personal styles, and heavy competition between colleagues. Teaching is not about information. It's about having an honest intellectual relationship with your students. Mentors can encourage mentees in teaching, research and career development. The successful mentor mentee relationship therefore requires the active participation of both parties. The aims of the present study were to facilitate the student's performance in the subject and to evaluate the effectiveness of mentorship programme.

\section{METHODS}

A cross sectional study was conducted on one hundred first MBBS (second semester) students in the Department of Biochemistry, RUHS College of Medical Sciences, Jaipur. After evaluation of the result of first semester in the subject biochemistry, a meeting of teaching faculty was organised in the department. The department chair proposed the concept of introducing mentorship programme and after detailed discussions it was unanimously decided to implement the programme. All six teaching faculty happily volunteered to play the role of mentor. At the start of second semester, each mentor was allotted students. Mentor's were asked to display ethical professional behaviour in order to serve as role models for students. The mentors were asked to counsel, guide and advice students (mentees).

Students (mentees) were randomly chosen for each mentor based on marks scored in first semester examination. Mentorship programme was undertaken for all students who scored excellent, very good, good average and below average marks respectively in the first semester examination. The period of the mentorship programme was 4 months. Interactions between Mentor-mentee were conducted weekly. Minimum $80 \%$ attendance was made compulsory for mentees for the sessions. Students could also approach mentors informally for advice and help. Mentors also monitored the mentees in day-to-day classes. Various techniques such as group teaching, individual guidance, assigning 
special tasks, extra practical classes, oral and written assessments, quiz and seminar were employed. The choice of technique used, varied individually by mentors depending on the performance and problems of mentees. Counselling was also given if any mentee had some social issues.

The marks of second semester were compared with the marks of first semester to analyse effectiveness of mentorship programme in context to improvement in performance. Database was collected in the form of feedback questionnaire. After completion of overall study of four months, student's and teaching faculty's feedback in the form of structured questionnaire, was collected to evaluate the experience of students and faculty as mentees and mentors respectively with reference to the formal and informal interactions in the mentorship programme. A theoretical thematic analysis $^{15}$ was made, where the data is coded for specific research questions. The analysis focused primarily on descriptive and interpretative levels. Statistical analysis was performed using Microsoft Excel t-test was applied and significance of the test was calculated by p-value.

Table 1: Comparison of marks scored in first and second semester examination pre- and postmentorship programme

\begin{tabular}{lccc}
\hline Biochemistry & $\begin{array}{c}\text { I Semester } \\
(\text { Mean } \pm \text { SD) } \\
(\mathbf{n}=\mathbf{1 0 0 )}\end{array}$ & $\begin{array}{c}\text { I Semester } \\
\left(\begin{array}{c}\text { Mean } \pm \text { SD) } \\
(\mathbf{n}=\mathbf{1 0 0})\end{array}\right.\end{array}$ & p value \\
\hline $\begin{array}{l}\text { Theory } \\
\text { Marks: 100 }\end{array}$ & $41.27 \pm 13.59$ & $63.72 \pm 13.13$ & $\mathrm{p}<0.0001$ \\
$\begin{array}{l}\text { Practical } \\
\text { Marks: 40 }\end{array}$ & $23.77 \pm 5.33$ & $27.04 \pm 3.45$ & $\mathrm{p}<0.0001$ \\
\hline
\end{tabular}

\section{RESULTS}

Table 1 depicts marks scored in second semester examination after mentoring the students. The mean \pm SD levels of theory and practical marks were observed statistically highly significant $(p<0.0001)$ in second semester when compared with marks of first semester examination. Table 2 depicts the transition of mentees to a higher score category post mentorship programme. The trend was similar in theory and practical marks. Figure 1 and 2 represents the response of mentor and mentee respectively to mentorship programme based on feedback taken (Table 3 and Table 4).

\section{DISCUSSION}

A true mentor fulfils a variety of roles in the professional development of the medical apprentice. The most important metric of successful mentoring is the success of the mentee. The findings as depicted in table 1 clearly indicate that mentoring enhances skills and intellectual development. The improvement in academic performance in practicals and theory suggests that mentorship programme affects psychomotor as well as cognitive domain of students. The psychological support offered by mentors also aids in developing affective domain. There is increasing evidence of the positive effects of mentoring in medicine ${ }^{16-18}$ and in medical undergraduate training programmes ${ }^{19-20}$.

Table 2: Distribution of students in respect to marks scored in semester examinations

\begin{tabular}{lcccc}
\hline Category & I Sem & I Sem & I Sem & I Sem \\
\cline { 2 - 5 } & $\begin{array}{c}\text { Theory } \\
\text { Marks } \\
\mathbf{1 0 0}\end{array}$ & $\begin{array}{c}\text { Theory } \\
\text { Marks } \\
\mathbf{1 0 0}\end{array}$ & $\begin{array}{c}\text { Practical } \\
\text { Marks } \\
\mathbf{4 0}\end{array}$ & $\begin{array}{c}\text { Practical } \\
\text { Marks } \\
\mathbf{4 0}\end{array}$ \\
$\begin{array}{l}\text { Excellent } \\
(\mathbf{8 0 \% )}\end{array}$ & - & 4 & 4 & 5 \\
$\begin{array}{l}\text { Very good } \\
(\mathbf{7 1 - 8 0 \% )}\end{array}$ & 1 & 28 & 15 & 28 \\
$\begin{array}{l}\text { Good } \\
(\mathbf{6 1 - 7 0 \% )}\end{array}$ & 4 & 36 & 27 & 49 \\
$\begin{array}{l}\text { Average } \\
(\mathbf{5 0 - 6 0 \% )}\end{array}$ & 25 & 19 & 33 & 15 \\
$\begin{array}{l}\text { Below average } \\
(<50 \%)\end{array}$ & 70 & 13 & 21 & 3 \\
\hline
\end{tabular}

Table 2 reflects the improvement in performance of students post mentorship programme. Maximum students scored marks in higher category in second semester examination as compared to first semester examination. This clearly indicates that effective 
Table 3: Perception of mentees regarding mentorship programme

Q. Questionnaire

No.
To a very
high

extent (1)

1. As a mentee do you think mentorship programme aids in knowledge acquisition. and to grow professionally

3. As a mentee do you think guidance from mentors improves your performance in assessments.

4. As a mentee did you get psychosocial support from your mentor.

5. Was mentor responsible and available to guide you when needed

6. As a mentee did you feel motivated to appropriately challenge yourself.

7. Did mentor aid in nurturing self confidence in you.

8. Did mentor offer wise counselling
14

9

$\begin{array}{ccc}\text { To a high } & \text { To some } & \text { Not at all } \\ \text { extent (2) } & \text { extent (3) } & \text { (4) }\end{array}$

(4)

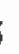

68

13

$\begin{array}{lll}77 & 13 & 1\end{array}$

$\begin{array}{llll}78 & 15 & 7 & 0\end{array}$

$\begin{array}{llll}9 & 64 & 21 & 6\end{array}$

$\begin{array}{llll}16 & 71 & 7 & 6\end{array}$

$\begin{array}{llll}73 & 21 & 5 & 2\end{array}$

$\begin{array}{llll}77 & 15 & 7 & 1\end{array}$

18
12

5

Table 4: Perception of mentors regarding mentorship programme

\begin{tabular}{|c|c|c|c|c|}
\hline $\begin{array}{l}\text { Q. Questionnaire } \\
\text { No. }\end{array}$ & $\begin{array}{l}\text { To a very } \\
\text { high } \\
\text { extent (1) }\end{array}$ & $\begin{array}{l}\text { To a high } \\
\text { extent (2) }\end{array}$ & $\begin{array}{c}\text { To some } \\
\text { extent (3) }\end{array}$ & $\begin{array}{c}\text { Not at all } \\
\text { (4) }\end{array}$ \\
\hline
\end{tabular}

1. Does being a mentor develop your teaching skills.

4

2. Does being a mentor develop your supervision skills.

3. Does being a mentor increased your interest for teaching. 5

4. Does being a mentor improved your relations with students. 3

5. Does being a mentor led to your professional development. 3

6. Do you think mentor has a role in improving performance 3 of students.

7. Do you think mentorship programme improves communication skills of students.

8. Did you face resistance from students for mentorship programme.
4

5

$-2$

3

$\begin{array}{lllll}1 & 2 & 3 & 4\end{array}$ 


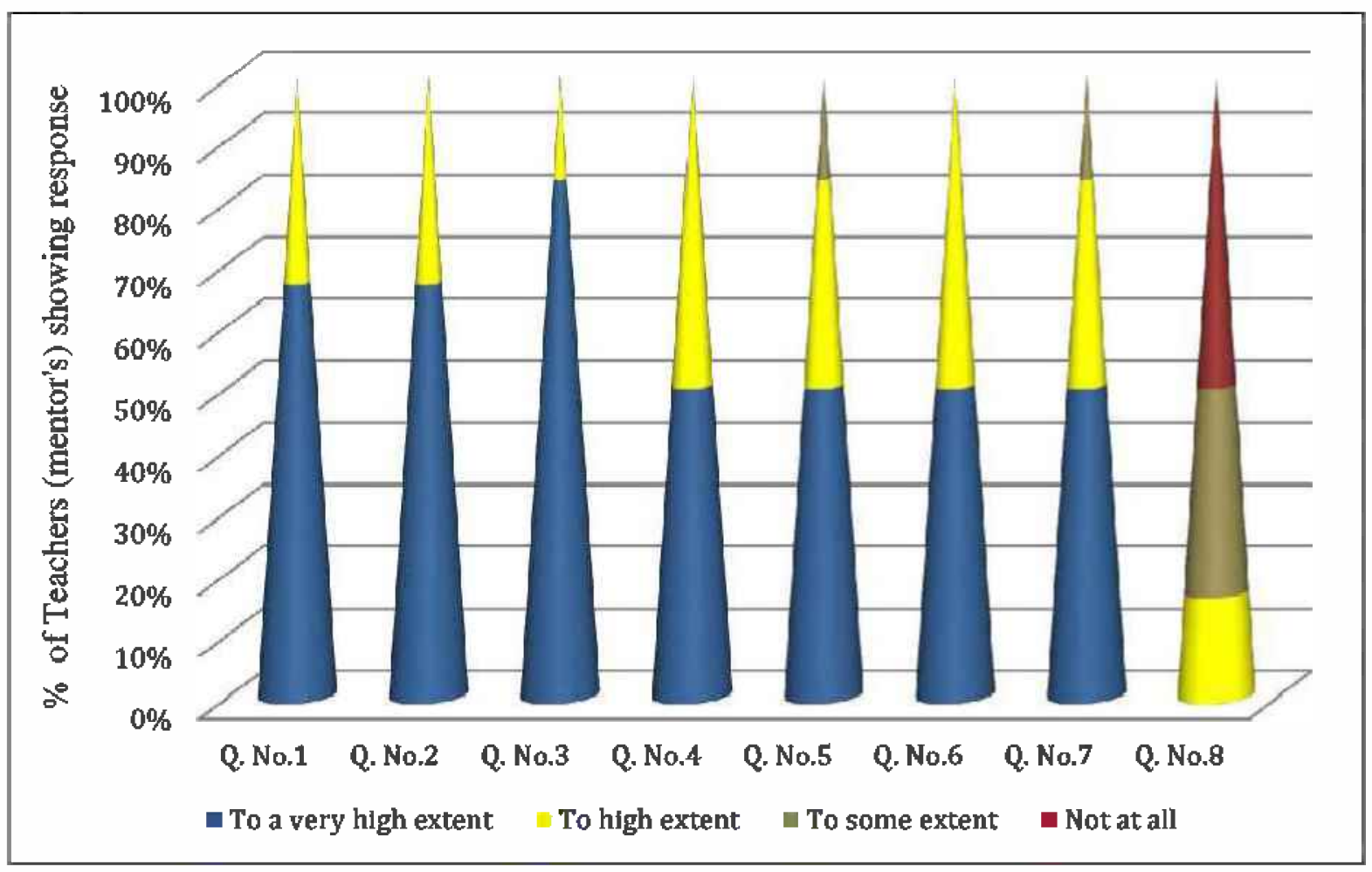

Figure 1: Representation of mentor's response to mentorship programme.

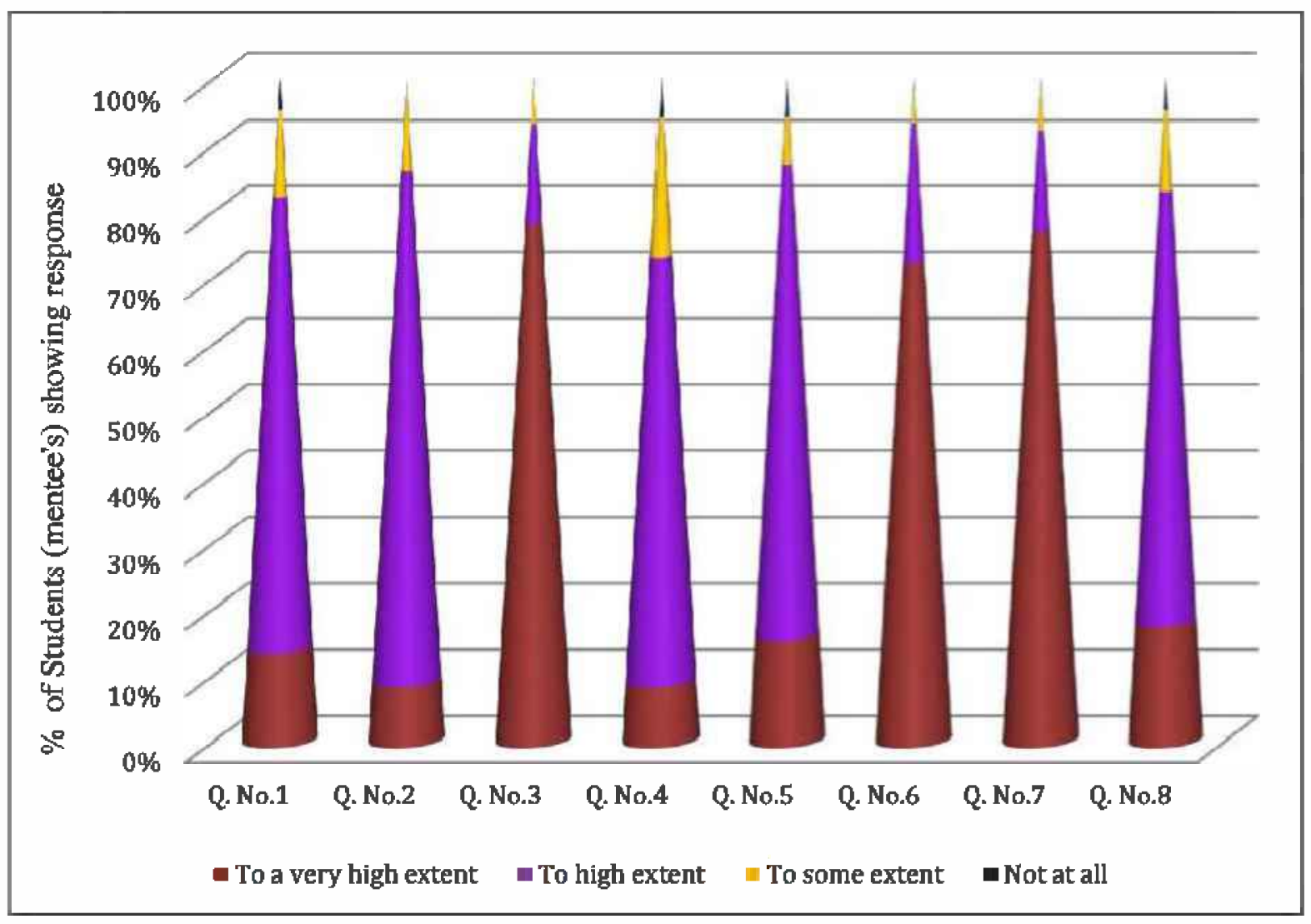

Figure 2: Representation of mentee's response to mentorship programme. 
mentoring is correlated with success. Our findings suggest that mentoring proves a boon for those who are perceived as poor academic achievers. An integral part of the mentoring process is the identification of unique areas of interest and expertise for mentees to pursue; this is driven by mentees who use their mentors as a resource. The goal should never be to clone mentors ${ }^{21}$.

The feedback as shown in Table 3 indicates that majority of the mentee's are of the opinion that mentors facilitate skill development and provide guidance and strategic advice. It has been reported earlier that a mentor may, for example, help the mentee to develop implicit knowledge about the hidden curriculum of professionalism, ethics, values and the art of medicine which cannot be learned from a text ${ }^{22}$. Psychosocial support and career development are the two classic forms of mentoring ${ }^{23}$.

The results of the present study are suggestive that informal teaching sessions also provide opportunities to increase expertise in presenting information. Students learn communication skills and gain self confidence. It was observed in the study that mentorship programme helped the students to be motivated and challenge themselves to excel in academics. Mentorship programme allows a mentee to be exposed to personal interaction to overcome all odds faced in the medical course whether related to subject matter or others.

The feedback of mentor's as shown in table 4 is reflective of the fact that being a mentor led to an increased interest in teaching and increased reflections regarding their own values and work practices. Majority of faculty claimed that being a mentor develops their teaching skills, increased their interest in teaching and improved their supervision skills. This is in accordance with other studies which report that mentoring benefits the mentors themselves ${ }^{12,16,24}$. The faculty was of the opinion that mentoring enhanced their relationship with students. Improvement in performance of students makes the mentor feel rewarded in academic life. Both satisfaction and difficulties experienced by mentors are closely related to the degree of student involvement in the activity. Mentoring can provide an important link between teaching and clinical practice. When it is part of a supportive, internal and non-hierarchical network, it can influence the professional culture itself ${ }^{25}$.

Consistent high-quality patient care can be accomplished only by a team-based approach in which systems need to be put into place to ensure the highest safety and quality of care. It is up to mentors to promote this concept of team-based care and continuous improvement to their mentees ${ }^{21}$. Mentors can share their experiences with earlier generations while learning newer paradigm-shifting technologies from their mentees. The authors suggest that an early implementation of mentorship programme at medical school is needed for attaining maximum positive outcomes and should be a continuous process throughout the medical course. A framework for approaching mentor-mentee interactions must be laid down in each institute making it a core component in training young professionals and to be introduced in first MBBS making it a virtuous cycle. Institutions need to encourage and recognize the value of a mentoring relationship.

\section{CONCLUSION}

The present study indicates that mentoring is a two way street benefiting students (mentees) as well as teachers (mentors) alike. Mentorship programme raises the performance bar of students and fosters the wellbeing and professional growth of students. Role of mentors as teachers is enhanced; motivated mentors are able to benefit students in becoming quality future doctors. In summary, the study lays emphasis on the importance of mentoring which can bring a wealth of expertise from the mentor's to students (mentee's) so as to develop and promote their professional development and it must be a continuous process throughout the medical course.

\section{ACKNOWLEDGEMENTS}

The authors are highly indebted to the Vice chancellor-RUHS, Dr Raja Babu Panwar for promoting medical education in the institute. We are grateful to Dr V M Katoch for his valuable guidance. The authors are thankful to the teaching faculty of department of Biochemistry without whose support the study could not have been possible and to the first 
year medical students for their active participation. Our thanks to Mr. Nagraj Soni for statistical analysis support.

\section{REFERENCES}

1. Mann MP. Faculty mentors for medical students: a critical review. Med Teach 1992; 14:311-19.

2. Ricer RE. Defining preceptor, mentor and role model. Fam Med 1998; 30:338.

3. Selwa LM .Lessons in mentoring .Exp Neurol 2003; 184: S42-7.

4. Standing committee on postgraduate medical and dental education: supporting doctors and dentists at work:An enquiry into mentoring 1998; London: SCOPME.

5. Souba WW. Mentoring young academic surgeons, our most precious asset. J Surg Res 1999; 82:113-20

6. Neacy K, Stern SA, Kim HM, Dronen SC. Resident perception of academic skills: training and impact on academic career choice. Acad Emerg Med 2000; 7:1405-08.

7. Frohlich ED. A renewed call to mentor (editorial). Hypertension 2000; 36:309-11.

8. Committee on pediatric research. Promoting education, mentorship and support for pediatric research. Pediatrics 2001; 107:1447-50

9. DeWitt DE, Curtis JR, Burke W. What influences career choices among graduates of a primary care training programme? J Gen Intern Med 1998; 13:25761.

10. Rock JA. Mentoring in gynecology: transactions of the 25th scientific meeting of gynaecologic surgeons, presidential address. Am J Obstet Gynecol 1999; 181:1293-5.

11. Pololi L, Knight S. Mentoring faculty in academic medicine: a new paradigm? J Gen Intern Med 2005; 20:866-70.

12. Garmel GM. Mentoring medical students in academic emergency medicine: keys to satisfaction. Acad Emerg Med 2004; 11:1351-57.

13. Hauer KE , Teherani A,Dechet A , Aagaard EM .Medical student's perceptions of mentoring : a focus - group analysis. Med Teach 2005;27:732-34.

14. Taherian K, Shekarchian M. Mentoring for doctors. Do its benefits outweigh its disadvantages? Med Teach 2008; 30: 95-9.

15. Braun $V$, Clarke $V$.Using thematic analysis in psychology. Qual Res Psyhcol 2006; 3:77-101.

16. Connor MP, Bynoe AG, Redfem N, Pokora J, Clarke J. Developing senior doctors as mentors : A form of continuing professional development. Report of an initiative to develop a network of senior doctors as mentors. Med Educ 1994-99; 34: 747-53.

17. Schrubbe KF. Mentorship: A critical component for professional growth and academic success. J Dent Educ 2004; 68:324-28.

18. Sambunjak $P$, Strauss SE, Marusic A. Mentoring in academic medicine. JAMA 2006; 1103-15.

19. Dorsy CE, Baker CM. Mentoring undergraduate nursing students assessing the state of science. Nurse Educ . 2004;29:260-65.

20. Buddeberg Fischer B, Herta KD. Formal mentoring programmes for medical students and doctors - A review of the Medline literature. Med Teach 2006; 28:248-57.

21. Holmes DR, Hodgson PK, Simari RD, Nishimura RA. Mentoring making the transition from mentee to mentor. Circulation 2010; $121: 336-40$.

22. Rose GL, Rukstalis MR, Schuckit MA. Informal mentoring between faculty and medical students. Acad Med 2005; 80: 34446.

23. Bellodi PL. Mentors, students and the undergraduate course: a virtuous cycle. Rev Bras Educ Med 2011; $35: 1-6$.

24. Centeno AM. How to enjoy your mentee's success and learn from it. Med Edu 2002; 36:1214-15.

25. Freeman R. Faculty mentoring programmes. Med Educ 2000; 34:507-08.

\section{Corresponding author:}

'Sonali Sharma,Professor and Head, Department of Biochemistry, RUHS College of Medical Sciences, Jaipur. (Raj).

e-mail: sonalisharma14@gmail.com 